\title{
2020: Mundo Pandêmico e os reflexos na região de Fronteira São Borja - Brasil e Santo Tomé - Argentina
}

\author{
2020: Pandemic World and Reflections in the São Borja - Brazil and Santo \\ Tomé - Argentina Frontier Region
}

\section{0: Mundo Pandémico y reflexiones en la Región Fronteriza São Borja - Brasil y Santo Tomé - Argentina}

\author{
Maurício Aires Vieira (profmauricioaires@gmail.com) \\ Professor Associado da Universidade Federal do Pampa/Campus Jaguarão. Doutor em Educação.
}

Dilossane Vargas da Silva (dilossane @ hotmail.com)

Doutoranda do curso de Ciências Humanas e Sociais pela Universidade Nacional de Misiones -

UNAM - Posadas Argentina

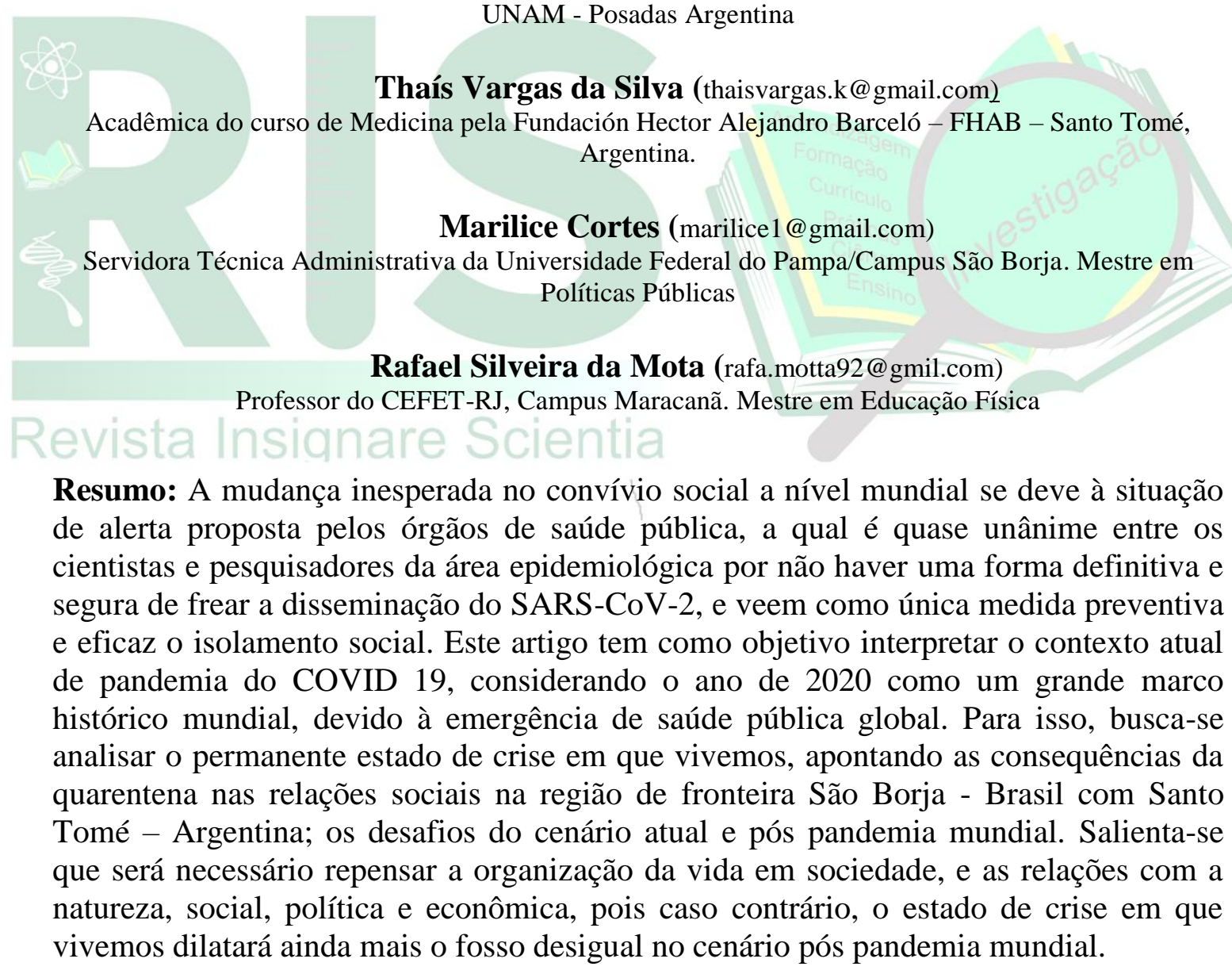

Palavras-chave: Pandemia; Quarentena; Crise; Tecnologia; Desigualdade Social.

Abstract: The unexpected change in social life worldwide is due to the alert situation proposed by public health agencies, it is almost unanimous among scientists and researchers in the epidemiological area that while there is no definitive and safe way to

Recebido em: $17 / 08 / 2020$

Aceito em: $1 \% / 12 / 2020$ 
stop the spread of SARS-CoV-2, the only preventive and effective measure is social isolation. This article aims to interpret the current pandemic context of COVID 19, considering the year 2020 as a major world landmark, due to the emergence of global public health. To this end, it sought to analyze the permanent state of crisis in which we live, pointing out the consequences of quarantine on social relations in the border region São Borja - Brazil with Santo Tomé - Argentina; the challenges of the current and postglobal pandemic scenario. It is stressed that it will be necessary to rethink the organization of life in society, and the relations with nature, social, political and economic, because otherwise, the state of crisis in which we live will further widen the uneven gap in the post-global pandemic scenario.

Keywords: Pandemic; Quarantine; Crisis; Technology; Social inequality.

Resumen: El cambio inesperado en la vida social en todo el mundo se debe a la situación de alerta propuesta por las agencias de salud pública, es casi unánime entre los científicos e investigadores en el área epidemiológica que si bien no existe una forma definitiva y segura de detener la propagación del SARS-CoV-2, la única medida preventiva y efectiva es el aislamiento social. Este artículo tiene como objetivo interpretar el contexto actual de pandemia de COVID 19, considerando el año 2020 como un hito mundial importante, debido a la aparición de la salud pública mundial. Con este fin, buscó analizar el estado permanente de crisis en el que vivimos, señalando las consecuencias de la cuarentena en las relaciones sociales en la región fronteriza de São Borja - Brasil con Santo Tomé - Argentina; Los desafíos del escenario de pandemia actual y post-global. Se enfatiza que será necesario repensar la organización de la vida en la sociedad y las relaciones con la naturaleza, sociales, políticas y económicas, porque de lo contrario, el estado de crisis en el que vivimos ampliará aún más la brecha desigual en el escenario de la pandemia post-global.

Palabras-clave: Pandemia; Cuarentena; Crisis; Tecnología; Desigualdad social.

\title{
1. INTRODUÇÃO
}

\begin{abstract}
Os únicos que verdadeiramente devem se envergonhar na China são aqueles que publicamente fizeram pouco caso da epidemia ao mesmo tempo que tomaram todas as medidas para proteger a si mesmos, agindo como aqueles funcionários soviéticos em torno de Chernobil que declararam publicamente que não havia perigo enquanto evacuavam imediatamente suas famílias, ou aqueles gestores de alto escalão que negam publicamente o aquecimento global, mas já estão comprando casas na Nova Zelândia ou construindo bunkers de sobrevivência nas Montanhas Rochosas (ZIZEK, 2020, p. 18).
\end{abstract}

A radical mudança no convívio social mundialmente se deve à situação de alerta proposta pelos órgãos de saúde pública, cientistas e pesquisadores da área epidemiológica que alertam não terem uma forma definitiva e segura de frear a disseminação de um vírus altamente transmissível e detentor de muitos óbitos, o SARS-

Recebido em: 17/08/2020

Aceito em: 1\%/12/2020 
CoV-2. Tais pesquisadores e cientistas diante de um novo e inesperado cenário, sem advento de cura relatam que a única medida preventiva e eficaz é o isolamento social. A problemática reside em analisar os reflexos desse novo contexto social inesperado e abrupto na região de fronteira São Borja - Brasil e Santo Tomé - Argentina, por ser um espaço histórico e de grandes movimentações pelas trocas socioculturais, econômicas, educacionais, diplomáticas e simbólicas. Para isso, busca-se interpretar as medidas governamentais tomadas pelos governantes destes países e apontar de que forma essas medidas vêm impactando na vida dos moradores deste espaço geográfico que tem o rio Uruguai como integrador sócio-histórico e natural.

\section{METODOLOGIA}

Este artigo busca explorar as primeiras informações e detalhamentos teóricos sobre a pandemia instalada/provocada pelo vírus. Buscamos os recortes mais atuais e os pronunciamentos dos executivos de ambos países que compõem a fronteira, assim como os decretos e outros documentos presidenciais. Autores que debatem o tema na atualidade e os indicadores dos consórcios de mídias digitais e televisivas foram apurados durante o primeiro semestre de 2020. Dados coletados são de fontes fidedignas e expostas à sociedade em geral através de sites governamentais e de jornais de grande circulação; ressaltamos que todos dados aqui expostos foram confrontados em duas fontes diferentes a fim de assegurar a fidelidade do dado ou informação ou conceito novo. Muitas informações, por carecerem, ainda, de grandes obras ou publicações são direcionadas em notas de rodapé para sua integralidade de fonte informacional. O texto apresentado nos leva a um diálogo com autores intercalados com tais dados coletados e comentados ao longo de toda exposição. Relatos e observações são importantes, principalmente pelos autores deste artigo, que vivem em uma região de fronteira, e trazem no corpo do texto suas vivências e olhares durante a pandemia, que não tem previsão de término e tranquilidade para a maioria das pessoas.

Neste estudo não se almeja aprofundar análises comparativas ou ideológicas, mas sim mostrar que de um lado da fronteira, em Santo Tomé - Argentina, temos uma realidade com medidas rigorosas em que as pessoas se encontram recolhidas em suas casas, pela preservação da vida. E do outro, São Borja - Brasil as medidas não restringem o direito à liberdade de ir e vir, ficando a cargo da consciência de cada um, ou até mesmo a falta dela.

\section{A CHEGADA E A INTERPRETAÇÃO DE VÍRUS}

Recebido em: $17 / 08 / 2020$

Aceito em: $1 \% / 12 / 2020$ 
O início de 2020 se deu de forma impactante, trazendo mudanças radicais a nível mundial, principalmente na vida das pessoas. Foi trazida à tona a disseminação de um vírus altamente transmissível, o coronavírus SARS-CoV-2 - COVID $19^{1}$ com origem, segundo a Organização Mundial da Saúde (OMS), que foi descoberto em 31/12/2019 após casos registrados na China, como um vírus microscópico (invisível) e letal. Diante da necessidade de enfraquecer a rápida expansão da pandemia do COVID 19, em todo o mundo pede-se que as pessoas fiquem em casa e promovam o distanciamento social; uma das alternativas viáveis de frear o avanço de casos e o colapso do sistema de saúde em várias partes do mundo.

A necessidade de uma quarentena (isolamento social, que dura em média, 14 dias, segundo divulgado por grandes mídias, jornais e pesquisadores da área da saúde) é devido à falta de estrutura na área da saúde para atender uma demanda maior de pessoas contaminadas, como: a falta de leitos, médicos, testes, respiradores, Unidade de Tratamento Intensivo - UTI, medicamentos e por ainda não ter sido desenvolvida uma imunização eficaz contra o vírus, como as vacinas já utilizadas pra outras doenças e/ou enfermidades. Portanto, se não houver o isolamento, teremos um colapso na área da saúde pela impossibilidade de atendimento simultâneo para todos os que, por ventura, irão precisar. Em vista disso, o que se clama mundialmente é a prática do isolamento social, para desacelerar a velocidade da contaminação e consequentemente possibilitar o atendimento médico hospitalar a todos que necessitarem.

Para Nakajima et all (2009) os CoVHs, mais conhecidos como coronavírus humanos, são os principais causadores de doenças respiratórias e está relacionado às infecções agudas respiratórias. Estas são causas de grandes casos de óbitos, na atualidade. O cenário atual está vivenciando um momento, classificado como de pandemia, onde uma doença infecciosa chamada por CoronavirusDisease 2019 (COVID-19), provocada pelo coronavírus da síndrome respiratória aguda grave 2 (SARS-CoV-2), está causando um verdadeiro caos em muitas cidades no mundo (GORBALENYA et all., 2020).

${ }^{1}$ Covid 19 - É uma doença causada pelo coronavírus SARS-CoV-2, que apresenta um quadro clínico que varia de infecções assintomáticas a quadros respiratórios graves. De acordo com a Organização Mundial de Saúde (OMS), a maioria dos pacientes com COVID-19 (cerca de 80\%) podem ser assintomáticos e cerca de $20 \%$ dos casos podem requerer atendimento hospitalar por apresentarem dificuldade respiratória e desses casos aproximadamente $5 \%$ podem necessitar de suporte para o tratamento de insuficiência respiratória (suporte ventilatório). Disponível em: https://coronavirus.saude.gov.br/sobre-a-doenca\#o-quee-covid.

Recebido em: $17 / 08 / 2020$

Aceito em: $1 \% / 12 / 2020$ 
Para Bahia (2020), esta doença cresce em progressão geométrica fazendo com que milhares de pessoas adoeçam e venham a óbito, tendo em vista sua alta taxa de contaminação e disseminação por organismos do corpo humano, debilitando-o, e até o momento sem medicação comprovada para frear os efeitos colaterais deixados. Por ser um vírus novo e ainda não se possuir nenhum tipo de imunidade e vacina, a OMS recomenda o isolamento social para que se possa retardar ao máximo a curva de crescimento da contaminação em massa da sociedade pelo COVID-19, e tentar oferecer uma infraestrutura que atenda todo sistema de saúde. Desta maneira, algumas pessoas poderão morrer mais rapidamente do que outras, por conta de diversos fatores associados à saúde e realidade do paciente.

O quadro de pandemia, fez com que o Brasil adotasse medidas de precaução; inicialmente, as mesmas utilizadas por outros países, que seria o isolamento social, a fim de evitar o colapso principalmente no sistema de saúde do país. Mas essa medida não foi bem vista por alguns detentores do poder executivo, incentivando, acima de tudo, a flexibilização desse isolamento em virtude da proteção da economia e dos problemas psicossociais que o isolamento poderia, em tese, causar, não declarando uma crise na saúde de alto poder devastador de mortes e indo contrário às medidas sanitárias de ministros de estado de saúde, da OMS e de uma maioria de países que passam pela mesma crise. (BAHIA, 2020).

Vale ressaltar que a contaminação pelo coronavírus em muitos países ocorreu de acordo com a previsão de crescimento exponencial, piorando a cada dia e colapsando o sistema de saúde, ao exemplo da Itália, Espanha, Estados Unidos, Brasil (Amazonas, Pará, Ceará e Rio de Janeiro inicialmente), cenas de covas sendo abertas ou câmaras frigoríficas eram comuns para atender os milhares de corpos que eram vencidos pela doença. Além de todo o caos que se estabeleceu no mundo, ainda há muitas pessoas aflitas com o medo da questão levantada sobre o debate da possibilidade de perderem seus trabalhos e/ou empregos informais. $\mathrm{O}$ vírus disseminado pela pandemia enfrentada na atual conjuntura é altamente transmissível, principalmente onde há uma maior concentração populacional e espaços reduzidos, o que no Brasil é a realidade de muitas famílias, ao exemplo dos presídios e das comunidades nos grandes centros urbanos, ou ainda das comunidades únicas em regiões de fronteira.

Um cenário que foi visto no início da pandemia no Brasil mostrou que antes da transmissão se tornar comunitária, o contágio era feito através dos patrões que voltavam de suas viagens e, mesmo com o vírus detectado ou a suspeita dele, não dispensaram 
seus funcionários e os mesmos se contaminaram em seguida. Considerando que as condições socioeconômicas são desiguais, enquanto os patrões, com seus planos de saúde, buscam a ajuda em hospitais privados, a maior parcela da classe operária depende do sistema único de saúde; e este tem como princípio a universalidade (não faz a distinção no atendimento) (BRASIL, 1990) e, mesmo com os investimentos nos hospitais de campanhas e os esforços dos profissionais da área, o sistema de saúde colapsou em muitos países e também no Brasil. Quem depende do sistema público para receber atendimento, precisa esperar por uma vaga (o que muitas vezes significa a perda de uma vida para a doença), deixando nas mãos do Estado a decisão de quem vive ou morre, priorizando sempre aquele indivíduo que possua algum valor para a sociedade (OLIVEIRA; BORGES E BEDINELLI, 2020).

A pandemia causada pelo novo coronavírus pode ser tão mortal quanto a pandemia de gripe de $1918^{2}$ e o número de óbitos pode ser ainda pior caso os líderes mundiais e as autoridades de saúde pública não consigam conter a atual disseminação do vírus adequadamente. $\mathrm{O}$ alerta foi dado por pesquisadores em um estudo publicado na revista médica JAMA Network Open, publicação cientifica vinculada à American Medical Association (Associação Médica Americana, em tradução livre), maior associação de médicos e de estudantes de medicina nos Estados Unidos.

\section{a. A PANDEMIA DO COVID 19 NA REGIÃO DE FRONTEIRA:}

\section{BRASIL X ARGENTINA}

Em São Borja, Rio Grande do Sul, fronteira com a Argentina as medidas de isolamento social ainda são consideradas brandas. Muitas pessoas, não estão conscientizadas da importância dos métodos de restrição e de higienização, e principalmente o significado da mensagem veiculada praticamente em todos meios de comunicação e nas redes sociais denominada ou intitulada "fiquem em casa". No outro lado da fronteira, em Santo Tomé na Argentina, as medidas de isolamento são mais severas, as pessoas podem deslocarem-se de suas casas tão somente para adquirir alimentos e medicamentos; tudo conforme as regras de segurança sanitária protocolos estabelecidos neste país, como forma de restringir da contaminação das pessoas da Covid 19.

\footnotetext{
${ }^{2}$ Ver livro da gripe;
}

Recebido em: $17 / 08 / 2020$

Aceito em: $1 \% / 12 / 2020$ 
Alberto Fernandez, presidente do país vizinho - Argentina, através do Decreto de Necessidade e Urgência - DNU 297/2020³, decretou na tentativa de combater a Covid 19 e como principal medida preventiva e obrigatório, o isolamento social para todas as pessoas, fazendo o seguinte questionamento ${ }^{4}$ :

(...) Tenho ouvido falar muito da angústia da quarentena. É angustiante salvar-se? Angustiante é ficar doente. Angustiante é que o Estado te abandone e te diga que faça o que quiser. Não que te diga para ficar em casa e que esteja presente. (...). Estamos numa pandemia que mata gente, entendido? Uma pandemia de um vírus desconhecido que não tem vacina nem remédio, entendido? Fiquem em casa e cuidem-se. Tentem levar isso da melhor maneira possível. Todos podem sair para espairecer quando quiserem, mas deixem de semear a angústia. Angustiante é que o Estado te abandone, que diga que não está acontecendo nada. Estão acontecendo coisas sérias. (...)

O posicionamento do Presidente argentino vem em primeiro lugar, em defesa da vida, pois estamos vivenciando uma transformação de paradigmas, em que ninguém em nenhum lugar estava preparado para enfrentar uma pandemia. Tanto que a solução encontrada mundialmente na tentativa de amenizar e evitar o contágio, ainda está sendo o isolamento social, como já mencionamos.

O Presidente brasileiro Jair Bolsonaro, tem outro ponto de vista, é defensor da abertura geral do comércio, e contra o isolamento social total. Demonstra preocupação com o impacto negativo do isolamento no desenvolvimento da economia do país, e tem o posicionamento de que somente o isolamento não salvará vidas ou o nosso próprio país. Questiona o uso de tratamento ainda sem comprovada eficácia dos pesquisadores e adota protocolos diferenciados junto ao combate da atual crise sanitária que vivemos. Conforme se pode observar em seu o pronunciamento à imprensa ${ }^{5}$ :

Em pronunciamento no rádio e na TV na noite desta terça-feira (24), o presidente Jair Bolsonaro afirmou que o novo coronavírus (Covid-19) está sendo enfrentado e pediu calma à população. "Sem pânico ou histeria, como venho falando desde o princípio, venceremos o vírus e nos orgulharemos", (...) Bolsonaro afirmou que as autoridades devem evitar medidas como proibição de transportes, o fechamento de comércio e o confinamento em massa. "Nossa vida tem que continuar. Os empregos devem ser mantidos. O sustento das famílias deve ser preservado. Devemos, sim, voltar à normalidade", destacou. Bolsonaro disse que as autoridades devem abandonar o conceito de "terra

\footnotetext{
${ }^{3} \mathrm{O}$ isolamento social se manteve de 20 de março até 30 de agosto de 2020, um dos maiores períodos de países vizinhos ao Brasil (com informações de agosto de 2020).

${ }^{4}$ Disponível em: https://www.osul.com.br/a-argentina-estende-a-quarentena-ate-dia-7-de-junho/

${ }^{5}$ Disponível em: https://www.osul.com.br/em-pronunciamento-bolsonaro-critica-imprensa-governadorese-isolamento-pelo-coronavirus-que-voltou-a-chamar-de-gripezinha/. Acesso em: 02/06/2020.
}

Recebido em: $17 / 08 / 2020$

Aceito em: $1 \% / 12 / 2020$ 
arrasada", a proibição de transportes, o fechamento do comércio e o confinamento em massa. O presidente voltou a se referir ao coronavírus como gripezinha. "No meu caso particular, pelo meu histórico de atleta, caso fosse contaminado, não precisaria me preocupar, nada sentiria, ou sentiria, quando muito, uma 'gripezinha' ou um 'resfriadinho'", afirmou. Jair Bolsonaro disse ainda acreditar na capacidade dos cientistas e pesquisadores para a cura dessa doença e falou que o governo recebeu notícias positivas sobre o uso da cloroquina no tratamento da Covid-19.

O governo brasileiro através do Ministério da Saúde disponibiliza diariamente boletins epidemiológicos sobre a situação da pandemia no Brasil e no mundo, e disponibiliza orientações sobre o impacto do COVID 19. Conforme o Boletim Epidemiológico divulgado em 06/04/2020, o país já tinha uma classificação que exigia alerta segundo a OMS, que apontava o Brasil como: Risco OMS global: Muito Alto. Risco pelo COE-COVID19 Brasil: Muito Alto. ${ }^{6}$

Conforme consulta a Organização Pan-Americana da Saúde (OPAS) a situação, referente ao número de mortos pelo Covid $19,{ }^{7}$ apresenta a disparidade de óbitos no Brasil comparados aos da Argentina, segue abaixo:

Quadro 1: Número de mortos pela COVID 19, data de panorama: 17/08/2020.

\begin{tabular}{|c|c|c|c|}
\hline País & População & N. de Óbitos & Vírus em circulação / habitante ${ }^{8}$ \\
\hline Brasil & 211.049 .519 & 107.879 & 3.339 .999 \\
\hline Argentina & 44.780 .675 & 5.246 & 268.574 \\
\hline
\end{tabular}

Fonte: Elaborado pelos pesquisadores, dados primários.

Os dados comparativos entre o número de óbitos pelo Covid 19, apresentados pelo Brasil com uma população de 211.049.519 habitantes e Argentina com 44.780.675 habitantes nos levam a considerar a importância dos posicionamentos dos chefes das nações. Este comprometimento reflete de maneira significativa no comportamento e comprometimento das pessoas, e consequentemente nas estatísticas de óbitos e acompanhamentos dos casos em evolução.

\footnotetext{
${ }^{6}$ Boletim Epidemiológico do Governo Brasileiro, Boletim-Especial-do-COE-Atualizacao-da-Avaliacaode-Risco.pdf. O acesso diário visualiza o crescimento do caso de óbitos e pessoas infectadas.

${ }^{7}$ Disponível > https://ais.paho.org/phip/viz/COVID19Table.asp. Acesso em: 23/07/2020.

${ }^{8}$ No Brasil, tanto o Presidente da República, e seus principais assessores, quanto o Governador do Estado do Rio Grande do Sul, também contraíram o vírus e conseguiram vencê-lo, voltando sua saúde à normalidade.
}

Recebido em: $17 / 08 / 2020$

Aceito em: $1 \% / 12 / 2020$ 
Quanto às restrições do acesso aos países, se observa que os postos aduaneiros da Argentina há restrições severas para a entrada de brasileiros e estrangeiros ao país. Já no Brasil o acesso está liberado não somente para os argentinos, mas para todas as demais nacionalidades.

No contexto atual, em decorrência da pandemia, os brasileiros estão impedidos de ingressar ao solo argentino e consequentemente de dar continuidade às trocas culturais, pontuando-se principalmente o comércio fronteiriço, visitação aos cassinos, busca pela comida típica, estudantes brasileiros os quais são atraídos pela variação cambial, ou simplesmente pelo acesso aos estudos no país vizinho. Essa situação extraordinária e atípica, imposta pelo governo argentino, em sua concepção se deu em decorrência da tentativa de evitar a transmissão do vírus e preservar vidas. Estas considerações antagônicas ganham relevância devido às relações sociais, econômicas, ambientais e culturais cultuadas por gerações entre estes espaços históricos e férteis interligados pelo rio Uruguai.

Nesta relação histórica de integração, deslocamentos sociais, comerciais, educacionais e culturais o rio Uruguai, destaca-se pela posição geográfica, e além da sua relevância para a navegação e escoamento da produção, sempre esteve no centro das ações e movimentações fronteiriças, e é a via para chegada e saída, como também conforme a variação cambial, definia-se em que lado do rio estava propício para a realização das práticas de eventuais contrabando.

\footnotetext{
O porto ou passo, é simplesmente, uma clareira escampada, no meio do mato, bastante incomodado para os que tinham mercadorias a embarcar e desembarcar, o território é de argila amarela e terra limosa e, consequentemente, de aluvião nova. São Borja (a povoação) está situada a mais de uma légua do porto. Por motivos óbvios, não existem cifras sobre o contrabando, mas o comercio lícito, no caso, serve de paradigma; pois quando a balança de troca, na aduana, se inclina para um lado, é sinal de que para esse penderam também a comercialização clandestina (ISABELLE, 1983, p. 17).
}

Salienta-se que neste espaço regional, mais tarde denominados de fronteira, desde o século XVI, via rio Uruguai, ocorriam intensas movimentações de povos indígenas oriundos da redução jesuítica de Santo Tomé em direção a fundação da redução de São Francisco de Borja. Muitos conflitos se delinearam nesta região, frutos de acordos políticos e econômicos bem como posteriormente, históricas arruaças 
oriundas da desobediência civil foram influenciadas pelas relações socioculturais do pampa.

Por volta do século $\mathrm{XX}$, com o auge do comércio formiga, dava-se o fortalecimento das práticas características de zona de fronteira, o auge do contrabando de gado, época em que a travessia do rio Uruguai ainda era realizada através de balsas, e os mais diversos produtos eram comercializados e transportados para o interior dos municípios da região da fronteira oeste do Rio Grande do Sul.

\begin{abstract}
A fronteira política para os setores populares da campanha oeste teve o significado de resistência social. Eles não reconheciam esses novos limites em decorrência de que, durante o séc. XVII e XVIII, o espaço da campanha conheceu um outro tipo de formação econômica e social, onde se formou uma memória coletiva e espacial, em que essa área ainda era percebida como um espaço comum, um espaço regional. Esse padrão cultural, articulado com as fronteiras políticas sulina e com a violência e a criminalidade adquiriam esse expressivo significado de resistência social. (PANIAGUA, 2003, p.177).
\end{abstract}

Desde o ano de 1997, a travessia de São Borja - Brasil para Santo Tomé Argentina ocorre via Ponte Internacional da Integração e nesse período, também foi criada a primeira Aduana Integrada de Fronteira na América do Sul. Destaca-se que as relações mencionadas anteriormente têm origens em um longínquo passado histórico missioneiro jesuítico-guarani.

\title{
Conforme Colvero,
}

descreve a formação dos povoados da fronteira oeste da província de São Pedro: São Borja, Itaqui e Uruguaiana. São Borja insere-se num contexto de formação jesuítica no qual houve uma transformação dos mais diversos setores a partir da ocupação definitiva dos portugueses em 1801, que levaram a fronteira a tornar-se uma das principais regiões de comercialização de produtos. (COLVERO, 2007, p. 15).

Frente a esse novo contexto a interpretação de fronteira nesse período de isolamento social, remontará a equivocadas conceituações de fronteira que tem como sinônimo separação/limite. O conceito de fronteira deve ser interpretado como um espaço comum, com predomínio e constância de trocas culturais, educacionais, ambientais, empresariais e simbólicas.

Diante desta pandemia, a vida dos fronteiriços também teve que se adaptar a uma nova realidade, devido à emergência de saúde pública mundial, advinda da propagação de um vírus até então pouco conhecido.

Recebido em: $17 / 08 / 2020$

Aceito em: $1 \% / 12 / 2020$ 
No Interior, a expectativa também é de forte recuo. Patricia Palermo, economista-chefe da Federação do Comércio de Bens e de Serviços do RS (Fecomércio-RS), lembra que os setores de varejo e serviços não essenciais é que estão pagando a maior parte da conta da crise. 'São os primeiros a serem afetados e os últimos a serem liberados'.

O governo argentino não esperou o Covid 19 atravessar a ponte, pois logo que, mundialmente, se soube que uma pandemia se alastrava fechou suas fronteiras, no entanto a crise econômica não pode ser barrada, pois o isolamento social está diretamente relacionado com a mesma, momento este que os governantes têm de optar pela sobrevivência econômica ou humana. Para o historiador Adelar (HEINSFELD, 2007, p. 19),

sob o prisma da Geopolítica, a abordagem do tema fronteiras, significaria (...) adentrar no campo das relações internacionais, envolvendo a política de um Estado em relação a outros e a segurança de seu próprio, integrados no princípio fundamental da soberania nacional, obriga o Estado a definir, no solo, no mar e no ar, os limites da área de poder.

A obrigatoriedade da quarentena ou isolamento social exigiu ajustes relacionados à mobilidade social, questões econômicas, acesso a serviços, e principalmente mudanças de hábitos e costumes. Nesta região de fronteira, São Borja/Santo Tomé, os reflexos da crise são sentidos em todos os setores da economia formal e informal, assim como as relações ambientais. Em tempos de pandemia, observa-se que a crise financeira está mais acentuada visto que as pessoas precisam se reinventar como forma de sustento para si e para sua família. Este novo paradigma social e econômico, vem através do comércio informal na confecção de itens de prevenção ao coronavírus, tais como: máscaras, produtos de higiene pessoal e de limpeza em geral, e serviços de tele entrega. Também contam com as redes de solidariedade das comunidades locais e auxílios governamentais.

Conforme Santos diz:

As vendas no balcão de loja, presentes no imaginário coletivo quando pensamos em varejo, nunca mais serão as mesmas. Assim como as aglomerações desordenadas em shoppings, especialmente em dias que antecedem datas comemorativas. O coronavírus impôs nova realidade e derrubou previsões de expansão do comércio para este ano, que muitos consideram ter acabado em meados de março, quando a pandemia começou a se alastrar no Brasil. Com o que avaliam ser o encerramento de um ciclo econômico, especialistas são unânimes em

${ }^{9}$ Disponível>.https://www.jornaldocomercio.com/_conteudo/cadernos/empresas_e_negocios/2020/05/738 628-a-reinvencao-do-varejo.html Acesso em: 02/08/2020.

Recebido em: $17 / 08 / 2020$

Aceito em: $1 \% / 12 / 2020$ 
afirmar que é hora de se reinventar e buscar novas estratégias de gestão, marketing e vendas. (...). (SANTOS, 2020, p. 02).

Durante a Pandemia Mundial do Covid 19, sociologicamente, descortina-se mais uma vez a realidade em que a desigualdade social aprofunda suas raízes históricas e afeta negativamente o desenvolvimento da sociedade. Em muitos países latinos, gera um abismo com consequências que afetam diretamente os direitos básicos garantidos pelas suas respectivas Constituições. Excepcionalmente, em momentos de dificuldade social, de crise em todos os setores, testemunham-se ricas manifestações de solidariedade de pessoas e ou grupos e instituições que comungam de valores humanos acima de tudo, principalmente expressos através do capitalismo. O cenário atual é um momento de reflexão e exercícios voltados para a análise e interpretação de qual é o papel ou função de cada cidadão e em contato com os demais, neste grande problema social. Preconizando a vida em sociedade, a relação com a natureza, a humanidade entre si, e a valorização da vida. Novas formas de interpretar o mundo e interagir nele, é necessário, a partir de agora.

Boaventura de Sousa Santos, na obra “A cruel pedagogia do vírus”, lança alguns questionamentos que nos conduzem a reflexão e também afirma que o mundo tem vivido em permanente estado de crise. (SANTOS, 2020, p. 01), onde ainda pondera:

Por exemplo, a crise financeira permanente é utilizada para explicar os cortes
nas políticas sociais (saúde, educação, previdência social) ou a degradação
dos salários. E assim obsta a que se pergunte pelas verdadeiras causas da
crise. O objetivo da crise permanente é não ser resolvida. Mas qual é o
objetivo deste objetivo? Basicamente, são dois: legitimar a escandalosa
concentração de riqueza e boicotar medidas eficazes para impedir a iminente
catástrofe ecológica. Assim temos vivido nos últimos quarenta anos. Por isso,
a pandemia vem apenas agravar uma situação de crise a que a população
mundial tem vindo a ser sujeita. Daí a sua específica periculosidade.
(SANTOS, 2020, p. 02).

Desde o ano de 1980, os reflexos do capitalismo aliado aos tentáculos neoliberais dominam e ditam regras para o mercado financeiro mundial e em contrapartida vivemos em um permanente estado de crise. Com o alargamento das desigualdades sociais, há o aumento de indivíduos que se enquadram na base da pirâmide social, trazendo como consequência a marginalização social, refletida no momento pela pandemia, visto que, teremos a agudização da crise em que esta faixa social está imersa. 
No século XXI, a pandemia do Covid 19, nos mostra que o ano de 2020 foi um grande marco na história da humanidade, devido à vivência massiva sob uma nova perspectiva proporcionada pelo período de reclusão do ser social e de suas atividades cotidianas. A era da tecnologia indubitavelmente ganha espaço, e o mundo pós Covid 19, trará sinais de modernização em diversas áreas e setores, tais como: educação, saúde, economia, ambientais, relações sociais, comunicação, relações diplomáticas, etc. Quanto ao aderir ao mundo digital, não se trata de querer ou gostar, mas sim de inserirse em um novo contexto mundial, com tendências pré-anunciadas, ou antecipadas, talvez, em algumas dezenas de anos. Como consequência da pandemia, o cenário que se abre aponta para novas perspectivas de vida, e mudança de comportamentos voltados para a valorização humana e social.

\subsection{OS REFLEXOS DA QUARENTENA E DO ISOLAMENTO NAS RELAÇÕES SOCIAIS}

Nesta transformação de paradigmas (intercambiamento social/isolamento social), o sistema capitalista, as relações sociais, os sistemas políticos terão a oportunidade de rever suas formas e espaços de atuação, e de preferência muito além da dicotomia saúde/economia, hoje foco dos parlamentares e dos chefes do executivo de nossos países. O contexto pós pandemia será outro, talvez com mais velocidade e maiores exigências, principalmente no âmbito das relações sociais e digitais; o mundo capitalista ainda ditará regras, momento este que o ser humano poderá endurecer, frente as necessidades de seus semelhantes. Mas será num novo modelo/mundo digital ou informatizado, à distância ou de caráter remoto, que termos que nos adaptar, aprender e ressignificar muitos conceitos, ações, atitudes, práticas profissionais e educativas.

Segundo Wust (2019) é nesse contexto de desafios e aprendizagens é que entenderemos que em meio aos desastres é que podemos ensinar a quem precisa; acontecem os imprevistos na nossa vida, rumos inesperados, porém o que mais precisamos é esperança para termos sempre a coragem necessária para superarmos os desafios, para com isso "melhor ensinar para bem aprender". Aprenderemos com o novo sobre algo novo e que ainda, não temos a plena convicção de como aprender para ensinar.

Os impactos da pandemia do Covid 19 nas relações sociais, parte do pressuposto que pós este cenário, as interações sociais não serão mais as mesmas. Hábitos de Recebido em: $17 / 08 / 2020$

Aceito em: $1 \% / 12 / 2020$ 
cumprimentar através do aperto de mão, abraços e beijos, certamente sofrerão readaptações. O abraço e o aperto de mão, característica das regiões fronteiriças ou interiorizadas tenderão a sumir por completo. Durante a pandemia, já está circulando o abraço virtual, e com todas as consequências negativas testemunhadas e vividas, advindas desta atípica situação global. O surgimento de novos comportamentos será inevitável para a retomada da vida em sociedade.

\begin{abstract}
O surto viral pulveriza este senso comum e evapora a segurança de um dia para o outro. Sabemos que a pandemia não é cega e tem alvos privilegiados, mas ao mesmo tempo assim cria-se com ela uma consistência de comunhão planetária, de algum modo democrática. A etimologia do termo pandemia diz isso mesmo: todo o povo. A tragédia é que neste caso a melhor maneira de sermos solidários uns com os outros é isolarmo-nos uns dos outros e nem sequer nos tocarmos. E uma estranha comunhão de destinos. Não serão possíveis outras? (SANTOS, 2020, p. 03).
\end{abstract}

Este alerta nos faz imergir em um pensamento unilateral imposto pela pandemia, dentro do qual o indivíduo pensando em si estará em consonância com o todo. Ainda chama atenção para a grande possibilidade da multiplicação não somente mundo a fora, mas intrinsicamente um olhar para nós mesmos para vislumbrar o outro. "Talvez baste abrir a janela", diz o escritor. (SANTOS, 2020, p. 05). Um momento de reflexão sobre a dominação econômica, política, cultural, da desigualdade social, de práticas históricas, de preconceito e discriminação em todos os sentidos, da falta de valorização da educação e dos professores, da falta de políticas públicas eficazes, as quais venham ao encontro de lacunas históricas que assolam indivíduos em condição desleal e muitas vezes desumanas, que exigem alternativas de superação frente ao sistema capitalista.

Santos (2020) propôs se a analisar a quarentena a partir da perspectiva daqueles e daquelas que tem mais sofrido com estas formas de dominação presente em uma sociedade em que padece o ser humano e impera a injustiça como consequência normal da exploração capitalista. Entre eles mulheres, idosos, trabalhadores informais, entre outros. (SANTOS, 2020, p.11).

Portanto, os reflexos da quarentena nas relações e interações sociais apontam para a continuidade de práticas históricas de violência. No contexto pós pandemia, para que "esse mundo" com tamanha desigualdade social, com práticas históricas de discriminação, preconceito, desumanidade e individualidade, faça parte do passado, ou seja, no outro lado do marco histórico. 
Devido à vulnerabilidade com que se apresenta a democracia, urge a emancipação política e social e principalmente de ações voltadas para mediar ideologias e elaborar propostas que venham ao encontro das necessidades e da emancipação do cidadão como um todo. A claridade pandêmica nos mostra a política comprometida e atuando como mediadora das aspirações dos mercados e divorciada das necessidades e aspirações dos cidadãos em vulnerabilidade social. Devido ao comportamento e a forma de atuação dos representantes políticos, e o descrédito na política faz com que as pessoas cada vez mais se posicionem no sentido inverso da participação política.

Rémond afirma:

Se antes, a História Política era acusada de tratar apenas de uma elite, de estudar apenas os que fazem da política a sua atividade profissional, agora seu objeto está no grande grupo, pois o princípio segundo o qual todos os cidadãos são iguais entre si e são chamados a participar das grandes escolhas políticas faz da política a "coisa de todos", mesmo que nem todos façam uso desse direito, todos são chamados e, mesmo que não se interessem pela política, “a política os alcança”. (RÉMOND, 1994, p. 18).

$\mathrm{Na}$ maior parte das vezes o que os cidadãos veem e sentem é a imensa desigualdade social. A concentração de renda nas mãos de poucos, e de forma não democratizada, a fome, a miséria, o analfabetismo, a violência, falta de saneamento básico, e água potável são fatores que contribuem para do distanciamento cada vez mais entre classes sociais, e principalmente em regiões de fronteira, que como sabemos acordos ou cooperações internacionais são falhas em vários sentidos. Estes contrapontos não são naturais e sim delineados com contornos definidos pela política capitalista, e neste mesmo quadro se pode visualizar e testemunhar a destruição da vida no planeta pelas mãos humanas e consideradas pelo capitalismo como racionais.

Como consequência da quarentena nas relações sociais na região de fronteira São Borja - Brasil com Santo Tomé na Argentina constatou-se que essas relações estão fisicamente restritas, mas virtualmente ativas.

\section{CONSIDERAÇÕES, AINDA NÃO FINAIS}

Na sociedade contemporânea, representantes políticos eleitos democraticamente, elaboram propostas de políticas públicas, voltadas para atender reivindicações que até então não contemplavam os anseios da população, e nem mesmo apresentavam projetos que viessem ao real encontro das necessidades básicas dos indivíduos que se encontram

Recebido em: $17 / 08 / 2020$

Aceito em: $1 \% / 12 / 2020$ 
na base da pirâmide social. Elas são mascaradas e voltadas para a ambição política do que para as necessidades emergentes

Busca-se a representatividade dos órgãos maiores de cada estado/nação, os quais foram eleitos democraticamente e possuem a função de serem gestores capacitados, para o desenvolvimento de políticas públicas, e implementando formas que venham ao encontro dos interesses da população, tendo seu compromisso de zelar por seus eleitores de forma transparente organizada e de estratégias. Vivemos um conflito ideológico, e ainda enfrentamos um coronelismo radical, embutidos em muitas vezes em uma falsa democracia, e

refletido em uma população sofre diretamente, pois há uma divergência de ideias e conflitos entre a ciência, empirismo e governantes (política).

Esperamos que durante a pandemia, e diante das manifestações globalizadas do Covid 19, este inimigo invisível, microscópico e devastador, a humanidade perceba que a ideologia capitalista, não intimida o inimigo invisível e letal, pois não escolhe classe econômica ou social e muito menos as barreiras geográficas, ou países distintos. Todos nós somos uma pessoa só, num contexto somente.

É fato que o vírus varreu o mundo, desbancou a economia e mostrou que a força do capital não está acima da vida, e como grande desafio, traz para o cenário atual o repensar a organização da vida em sociedade e das relações sociais, ambientais, políticas e econômicas. Caso contrário, o estado de crise em que já vivemos dilatará ainda mais o fosso desigual no cenário pós pandemia mundial.

Em tempos de crise, na região de fronteira que compreende São Borja no Brasil e Santo Tomé na Argentina, as dificuldades socioeconômicas aprofundaram-se ainda mais, devido à mudança de rotina e principalmente pelo fechamento do comércio em Santo Tomé, no país vizinho. Em São Borja, a restrição ao comércio foi por pouco tempo, mas também significativo na mudança de hábitos dos samborjenses. Interpretamos, mesmo que momentaneamente, que independente da redução de receitas comerciais nestes municípios os reflexos da crise pandêmica os atingiram em todos os segmentos. Neste contexto de pandemia, devido as pessoas estarem em isolamento social, a quarentena desacomodou os arredios fronteiriços em relação ao uso da tecnologia, dessa forma como mais um desafio do cenário atual, está posto as relações sociais virtuais, mas este desafio não se restringe somente a estas relações, destaca-se 
também a comunicação e as relações comerciais, que estão em ritmo ascendente ao encontro da tecnologia e do ambiente virtual, que poderá nos trazer algumas respostas futuras ou formas de comunicação, mas jamais trará nosso mundo e nossa fronteira no estado anterior e resiliente à devastadora pandemia que enfrentamos.

\section{REFERÊNCIAS}

BAHIA, Lígia. Judicialização da Saúde. 2014 Disponível em: http://www6.ensp.fiocruz.br/visa/?q=node/5995. Acesso em: 09 maio 2020.

COLVERO, Ronaldo. Negócios na Madrugada. O comércio ilícito na fronteira do Rio Grande do Sul. Editora Universitária UPF, 2004.

GORBALENYA, Alexandre. et al. Severe acute respiratory syndrome-related coronavirus: The species and its viruses - a statement of the Coronavirus Study Group. bioRxiv (versão em inglês). Disponível em: https://www.biorxiv.org/content/10.1101/2020.02.07.937862v1.full. Acesso em: 09 Abr. 2020. doi: https://doi.org/10.1101/2020.02.07.937862.

HEINSFELD, Adelar. Fronteira Brasil/Argentina: a Questão de Palmas - de Alexandre Gusmão a Rio Branco. Méritos Editora. Passo Fundo, 2007.

IBGE - Instituto Brasileiro de Geografia e Estatística. Projeção da população. Disponível em: https://www.ibge.gov.br/apps/populacao/projecao/. Acesso em: 2 jul. 2020.

ISABELLE, Arsene. Viagem ao Rio Grande do Sul (1833-1834), Martins Livreiro, 1983.

JORNAL DO COMÉRCIO. A reinvenção do varejo. Disponível em: https://www.jornaldocomercio.com/_conteudo/cadernos/empresas_e_negocios/2020/05/ 738628-a-reinvencao-do-varejo.html Acesso em: 02/06/2020.

JORNAL O SUL. Disponível em: https://www.osul.com.br /em-pronunciamentobolsonaro-critica-imprensa-governadores-e-isolamento-pelo-coronavirus-quevoltou-a-chamar-de-gripezinha/. Disponível em: https:/www.osul.com.br Acesso em: 02/06/2020.

MINISTÉRIO DA SAÚDE DO BRASIL. Coronavírus: 149, 9 mil pessoas estão curadas no Brasil. Disponível em: https://www.saude.gov.br/noticias/agenciasaude/46933-coronavirus.\%20/ . Acesso em: 2 jul. 2020.

MINISTÉRIO DA SAÚDE DO BRASIL. COVID 19 - É uma doença causada pelo coronavírus SARS-CoV-2. Disponível em: https://coronavirus.saude.gov.br/sobre-adoenca\#o-que-e-covid. Acesso em: 05 jul. 2020.

MINISTÉRIO DA SAÚDE DO BRASIL. Especial: Doença pelo Coronavírus 2019. Disponível em: https://www.saude.gov.br/images/pdf/2020/April/06/2020-04-06---BE7-

Recebido em: $17 / 08 / 2020$

Aceito em: $1 \% / 12 / 2020$ 
--Boletim-Especial-do-COE- Atualizacao-da-Avaliacao-de-Risco.pdf. Acesso em: 2 jul. 2020.

MINISTÉRIO DE SALUD - ARGENTINA. Aislamiento social, preventivo y obligatorio. Disponível em: https://www.argentina.gob.ar/salud/coronavirus- COVID19. Acesso em: 2 jul. 2020.

NAKAJIMA N, HATA S, SATO Y, TOBIUME M, KATANO H, KANEKO K. The first autopsy case of pandemic influenza (A/H1N1pdm) virus infection in a Japan: detection of a high copy number of the virus in type II alveolar epithelial cells by pathological and virological examination. Jpn J InfectDis. 2009 Jan;63(1):67-71.

OPAS / OMS BRASIL. Folha informativa - COVID-19 (doença causada pelo novo coronavírus). https://www.paho.org/bra/index.php?option=com_content $\&$ view=article \&id=6101: covi d19\&Itemid=875. Acesso em: 2 jul. 2020.

PANIAGUA, Edson Romario Monteiro. Fronteiras, violência e criminalidade na região platina: o caso do município de Alegrete. Dissertação de Mestrado. São Leopoldo, UNISINOS, 2003.

RÉMOND, René. Por que a história política? Revista Estudos Históricos. Rio de Janeiro, volume 7, número 13, 1994.

RÉMOND, René. Por uma História Política. $2^{\circ}$ ed. FGV, 2010.

SANTOS, Boaventura Souza. A cruel pedagogia do Vírus. Coimbra: Editora Almedina, 2020.

WUST, Naiára Berwaldt. Minha primeira experiência como Professora de Biologia: desastres e esperanças. Revista Insignare Scientia - RIS, v. 2, n. 3, p. 214-221, 21 nov. 2019.

ŽIŽEK, Slavoj. Pandemia recurso eletrônico: covid-19 e a reinvenção do comunismo (tradução Artur Renzo) 1. ed. - São Paulo: Boitempo, 2020. 